It is remarkable that the terms 'transition state' and 'critical complex' do not occur in an index with more than 700 entries, and that the quasi-thermodynamic method is scarcely used at all in the book. It is true that the statistical equations of the transition state method are worked out in an appendix, but (sis the author himself points out) they are of little service in predicting absolute reaction-rates in solution. The value of thermodynamic analogy does not lie in detailed calculation, but in the insight which it gives into the parallel effects of various factors (temperature, pressure, solvent, etc.) on reaction velocities and on equilibria. This aspect of the matter has not been clearly dealt with, and the chapter on "Equilibria" is concerned chiefly with the reverse process of explaining equilibrium constants in terms of kinetic considerations. At best, this procedure provides a derivation of familiar relations which is cumbrous and of limited validity, and at times it produces some curious results, for example (p. 196), an expression for an electrolytic dissociation constant which involves the viscosity of the solvent. This chapter might with advantage have been curtailed, or even omitted altogether.

It is possible to criticize a number of the author's detailed statements ; for example, that an observed reaction order of two shows the slowest step to be bimolecular (p. 49), and that the slowness of esterification reactions in the gas phase must be due to a low collision factor (p. 242). However, in spite of this, and the more general criticisms indicated above, the author has given a useful survey of much recent material. If he has at times failed to give a clear picture of its significance, this is due, at least in part, to the great bulk of experimental work, and to the many and diverse interpretations which have been advanced.

R. P. BeLL

\section{PROPERTIES OF SLOW ELECTRONS IN GASES}

\section{Electrons in Gases}

By Sir John Townsend. Pp. viii + 166. (London: Hutchinson's Scientific and Technical Publications, n.d.) $25 s$.

$\mathrm{D}$ ISCHARGE phenomena, which may be as varied as lightning, the operation of counters, or the growth of photo-electric currents, all depend upon the mechanics of electrons in gases. Any picture of those processes which involve electron and atom collisions must be built upon experimental determinations of such factors as the atomic cross-section and the fractional loss of energy in collision. Further, the related entities of electron-drift speed and energy of agitation, or temperature, and probably the process of attachment also, depend upon those factors through the electron-energy distribution function. This function depends upon the electric intensity, the gas concentration, and on the variation of atomic cross-section with velocity, and thus varies from gas to gas in a manner which, for any given case, is at present best found experimentally.

For this reason the subject-matter of "Electrons in Gases" is of fundamental significance. The experimental work described is mainly that carried out by Sir John Townsend and his collaborators in Oxford since the publication of his treatise "Electricity in Gases"; and the present book, which is a research monograph, makes an interesting sequel. The description of the determinations of the mean electron energies and the atomic cross-sections for slow electrons by the diffusion method is very useful, as this technique has proved to be powerful and of wide appl cation. In the higher energy range the results are fundamental in discharge physics; but recent work on the interaction of radio waves in the ionosphere shows that the technique is also capable of giving important data in this field, where the electron energies are comparatively low and do not greatly exceed thermal values.

The book is confined mainly to giving the theory of the experimental methods and the results obtained : space does not permit full discussion of theoretical derivations of energy-distribution functions when considerable excitation and ionization occur. Except for a treatment of the electric spark at low pressures, other discharge phenomena lie outside the scope of the book: such applications have been treated in Townsend's earlier treatise and in later books on the subject by others. On the other hand, valuable data on the ionization coefficients in pure monatomic gases are given, and the book, which unfortunately lacks an index, can be strongly recommended to those engaged in research in this field.

\section{F. LlEWELLyN Jones}

\section{PARTHENOGENETIC PATERNITY IN CENTRAL AUSTRALIA}

\section{Aranda Traditions}

By T. G. H. Strehlow. Pp. xxii + 18I + 10 plates. (Melbourne: Melbourne University Press, 1947.) $17 s .6 d$. net.

TN the early days of the discovery of Australia by $\mathcal{I}$ the whites, the aboriginals, or black fellows, were stigmatized as degenerate, treacherous and quite untamable. More sympathetic study of these people has, however, rather changed this uncompromising attitude, and once the language difficulty is overcome a far juster estimate of their character can be made. The author of this book was brought up in close contact with the Aranda, able not only to speak their language, but even to think in it. He is able, therefore, to describe their ceremonies and transcribe their chants and folk-tales accurately and feelingly, combining the point of view of the participant with that of the observer. Some previous students of the Aranda have not realized the extent to which the northern, western and southern divisions varied from each other, so that little generalization can be made as to customs and ceremonies as a whole. But by limiting the study to one area (in the first section of the book the northern Aranda area in Central Australia) the author is able to give a reasonably full account of the myths and religion of a strongly patriliniar group.

These myths are mostly brief accounts of the lives of totemic ancestors handed down by word of mouth by the old men to young initiates, usually on the occasion of a visit to the local spot where the tjurunga or sacred sticks and stones are hidden. By the power of their superior knowledge, the old men hold absolute authority in all matters of religion and custom, and there is no outlet for any creative impulse in the younger generation. Every possible site in the territory has already been assigned its own spirit or myth, and there is nothing left to the 